\title{
Rehabilitation of maxillectomy defect with obturator prosthesis
}

\author{
Dr. Ashwini M Khandare ${ }^{1}$, Dr. Ravikumar Akulwar ${ }^{2}$, Dr. Ashwin Kodgi ${ }^{3}$ \\ 1(Lecturer, Department of Prosthodontics/MIDSR Dental College Latur, India) \\ 2(Reader, Department of Prosthodontics/MIDSR Dental College Latur, India) \\ 3(Lecturer, Department of Prosthodontics/MIDSR Dental College Latur, India)
}

\begin{abstract}
The acquired defects of the palate are created commonly surgical intervention of benign or malignant neoplasms. The size and location of the defect influence the level of difficulty in prosthetic rehabilitation. Surgical intervention creates anatomic defect which forms communication among the oral cavity, nasal cavity and maxillary sinus. The goal of prosthodontist is to rehabilitate missing oral and extra oral structures with restoration of normal anatomic and physiologic function. Prosthetic rehabilitation with obturator restores the oral structures and also acts as barriers between communications among the cavities.
\end{abstract}

Key words: Maxillary defect, Obturator, Oro antral communication

\section{Introduction}

Acquired maxillary defects of the palate are seen in patients suffering from benign and malignant neoplasms, trauma, pathologic changes, radiation therapy and surgical intervention. Ablative surgical therapy is frequently adopted for the control of malignancies and other abnormal growths. This results in anatomic defect that allows the oral cavity maxillary sinus and nasal cavity to become one compartment, abrupt alteration of physiologic functions such as speech, mastication, deglutition and salivary control. Prosthodontics rehabilitation for an acquired maxillary defect begins immediately at the time of surgical resection. Prosthetic rehabilitation begins with a surgical obturator, which is inserted at the time of surgery to help retain the packing, prevent oral contamination of the surgical wound and skin graft, and to allow the patient to speak and swallow during the initial post operative period. The surgical obturator is commonly converted into an interim obturator with the addition of resilient lining material to adapt to the defect. Definitive obturator is initiated approximately 3 to 4 months after surgery when healing is complete. The impression for definitive obturator prosthesis should include the skin graft mucosal junction, lateral aspect of the orbital floor, and the dynamic physiology of the velopharyngeal mechanism during speech and swallowing. The obturator bulb must also be contoured to prevent obstruction of nasal breathing and to maintain nasal resonance during speech. The degree of extension into the defect varies depending upon the configuration of the defect, character of its lining tissue, and functional requirement for retention, stability and support of the prosthesis. This article describes a case report of a patient who had undergone partial maxillectomy secondary to squamous cell carcinoma and rehabilitated with definitive obturator.

\section{Case Report}

A 50 years old male patient reported with a chief complaint if inability to masticate, fluid leakage into the nasal cavity and nasal twang. His past medical history revealed that he underwent left partial maxillectomy. Intra oral examination showed aramany class I maxillary defect on the left maxilla (Fig.1, 2). His remaining teeth were present on the unaffected side. Patient used an interim obturator for the past 6 months. Intra oral examination revealed well healed surgical defect in the maxillary left palate creating an oro-antral communication [1-5].

All remaining teeth were examined clinically and radio graphically and found to be caries free with no significant gingival or periodontal problems. Because of missing maxillary structures masticatory and phonetic functions of patients were severely affected. Radiographic examination showed large radiolucency in the maxillary left palatal region. The patient was diagnostically classified as class IV (severely compromised) clinical situation according to the prosthodontic diagnostic index (PDI). Prosthetic rehabilitation was planned with a definitive obturator.

\section{Technique:}

Primary impressions were made using irreversible hydrocolloid impression material. Primary casts were obtained and special tray was fabricated and final impression was made using elastomeric impression material and master cast was obtained. Retentive clasps were made on right central incisor, premolars and molar [6]. Wax up was done to obtain permanent denture base [7-8]. On this the oclusal rims were made. Jaw relation was recorded using face bow and it was articulated on the semi adjustable articulator (Fig. 3, 4). Teeth 
arrangement was done (Fig. 5) and trial was done (Fig. 6). This was flasked and packed using heat cure acrylic resin [9-10]. Denture insertion was done and the defect side was relined with the resilient liner (Fig 7-11). The patient was recalled after 2 days.

\section{Discussion}

This article describes a relatively simple and less time consuming technique to fabricate a definitive obturator. In dentate patients, primary retention, support and stability of an obturator depend on the number and distribution of the remaining teeth. Engagement of soft tissue undercuts including scar band at the skin graft mucosal junction, may also play a significant role particularly in edentulous patients. Wide surgical resections for the control of malignancies frequently result in a small number of remaining unilaterally clustered teeth. These remaining teeth serve as abutments for the obturator.

The skin mucosal graft junction scar band will also stretch out over time and become ineffective in helping to retain the obturator. A stable record base is critical for recording an accurate maxillomandibular relationship and in evaluation of the esthetics and phonetics of the wax trial prosthesis. The fit and stability of the record base for an obturator however is often compromised because of the size of the surgical defect and is further compounded by the need to block out undercuts and by the under extended borders [7-8]. A processed record base provides maximum support, retention and stability for a maxillofacial prosthetic patient and additional steps of relining the record base can be avoided.

\section{Conclusion}

Although it is very difficult to improve the quality of life for hemimaxillectomy patients compared to the conventional prosthesis. But this can be achieved with good skill, experience and knowledge of the specialists. The definitive left partial definitive obturator for a patient resulted in regaining loss of functional and anatomic continuity and also provided psychological well being of the patient.

\section{References}

[1]. Aramany MA. Basic principles of obturator design for edentulous patients: Part I: classification. J Prosthet Dent. 40, 1978, 554-557

[2]. Aramany MA. Basic principles of obturator design for edentulous patients: Part II: classification. J Prosthet Dent.40, 1978, 656-662

[3]. Beumer J, Curtis TA, Firtell DN. Maxillofacial rehabilitation, prosthodontics and surgical considerations. The C. V. Mosby Company: St Louis; 1979. 188-243

[4]. Desjardins R, Obturator prosthesis design for acquired maxillary defects. J Prosthet Dent 39, 1978,424

[5]. Taylor TD, Clinical maxillofacial prosthetics. Quintessence publishing Co, Inc: 2000. 103-120

[6]. Parr GR, Tharp GE, Rahn AO. Prosthodontics principles in the framework design of maxillary obturator prostheses. J Prosthet Dent. 62, 1989, 205-212

[7]. Jacob RF, Yen TW: Processed record bases for the edentulous maxillofacial patient. J Prosthet Dent 65, 1991, 680-685

[8]. Murata H, Hamada T, Nagasiri R: Stabilizing record bases for edentulous obturator prostheses with silicone resilient lining material. J Prosthet Dent 82, 1999, 366-368

[9]. Naveen YG, Sethuraman R, Prajapati P: Definitive obturator prostheses. Int J Prosthet Dent 2(1), 2011, 22-26

[10]. Kurian B, Kumar R, Shajahan P. Maxillectomy defect rehabilitation with obturator prosthesis - a case report. IJCD 2(6), 2011, 118121

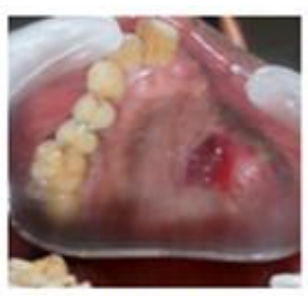

F.; 1-maxillay dafect

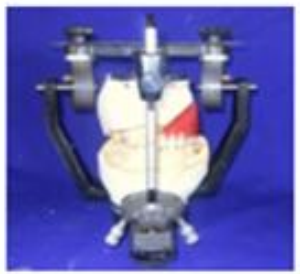

Fig t-arsedation

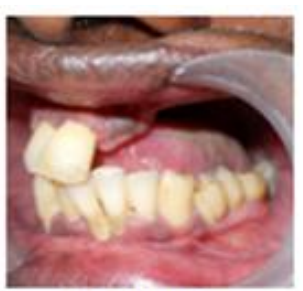

Faz-6afact wide

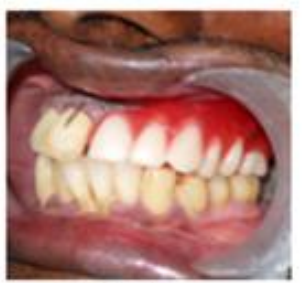

$F \cdot 5: 3 y=$

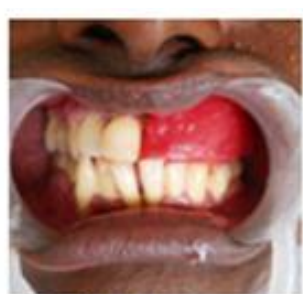

F.g 3-jawralation

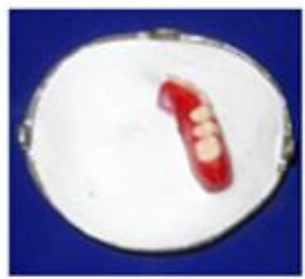

Fig 5-faviong wht
p4:manuz dozm=0 

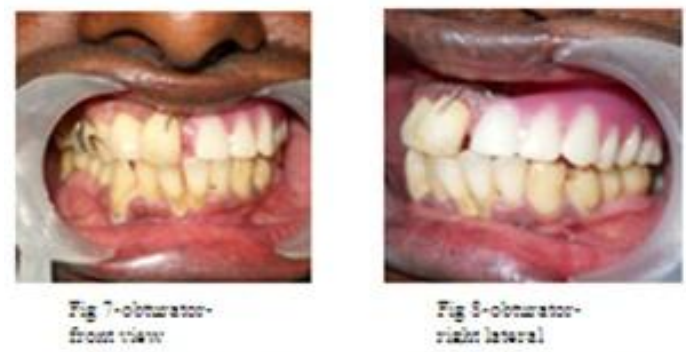

Fis sobensm-

rista has:

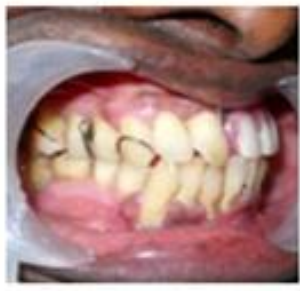

F.g7-maxily

Gofoctolat aves

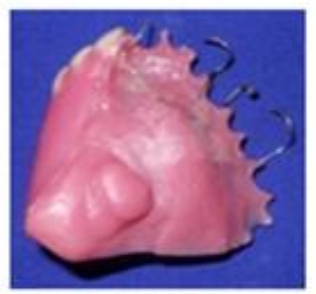

F.g 10-06acans

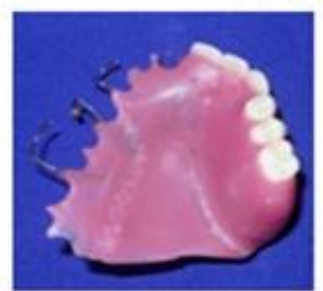

Fig $11 \cdot 0$ berase:

ingionsefast 